\title{
Review of DNA Computing And Its Application in Complex Problems Solvation, Adelman Problem Solution in Using of DNA Via Experimental Methods
}

\author{
Mostafa Omidi ${ }^{1}$, Mohsen Alipour ${ }^{2}$ \\ ${ }^{1,2}$ Technical Department, Azad University Branch of Tehran, Center
}

\begin{abstract}
In this article the using of novel generation of computers will be pointed that use some chips from the DNA type replace to silicon ones. Their structure is similar to biologic DNA.So, it should be possible to generate these DNA strings in lab and uploaded needed information on them and after that the results of DNA string converted to an apprehensible model for human. This process needs working with devices related to biology. Upon to performed experiments, the DNA strings have the considerable speed in calculation than silicon chips and also the return result of these chips always are true.In this article a simple and applied sample will be explained. Also the disadvantages and flaws of these kind of chips will be clarified.
\end{abstract}

Keywords: Silicon chips, DNA, DNA Computing, Silicon chips, Hamilton path

\section{Introduction}

Nowadays, using of computer expanded that maybe living without it is impossible, computer data and information increased consequently. Increasing the quality of these data needs the bigger and huger memories and of course the more rapid transmission and more rapid data processing. During the general processing some time needs to be patient for processing and result return. Aforementioned reasons caused the idea about the usage of non-silicon processors. One of these processors is DNA strings.DNA Computing is a novel method with biomolecule structure of DNA strings that can be high interested, novel and improvable.

Adelman (1994) as the first study in this field used the DNA strings, solving the Hamilton problem or Traveling Salesman Problem. This study showed the ability of DNA strings in problem solving with high speed and completely true result. In addition, this study revealed that general problems, which solved by logical formulas via digital processors can be solved in less time, using the DNA strings parallel structure. TSP or Hamilton problem is one of the most difficult problems because it has various possible states.

\section{DNA and DNA Computing}

At first, it needed to define the expressions of this field precisely.

\subsection{What is the DNA?}

DNA is abbreviation ofDeoxyribonucleic Acid and is the smallest part of live organism cells. In a DNA molecule deoxy nucleotides link to each other in a polymer structure, this link called phosphodiester bond.Each nucleotide has individual properties and there are four type of nucleotides (figure 1).

- A: Adenine

- T: Thymine

- C: Cytosine

- G: Guanine

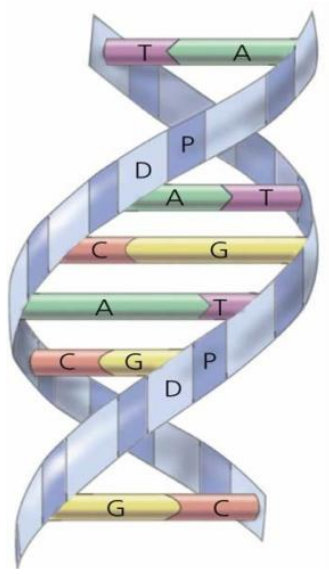

Fig1. A DNA string with nucleotides and Complement strings 
A DNA string Synthesized naturally at environment but sometimes these strings provided as pair called DOUBLE HELIX, can also make them out of cell. There is a rule for DNA string coupling, called Watson-Crick rule, just the A nucleotide pairs with $\mathrm{T}$ and $\mathrm{C}$ with $\mathrm{G}$.

\subsection{What is the DNA computing?}

A novel method uses the DNA, biochemistry and molecular biology for computing instead of silicon-based computers (figure 2). Consequently, the biochemistry and molecular biology experts will be active in this domain.
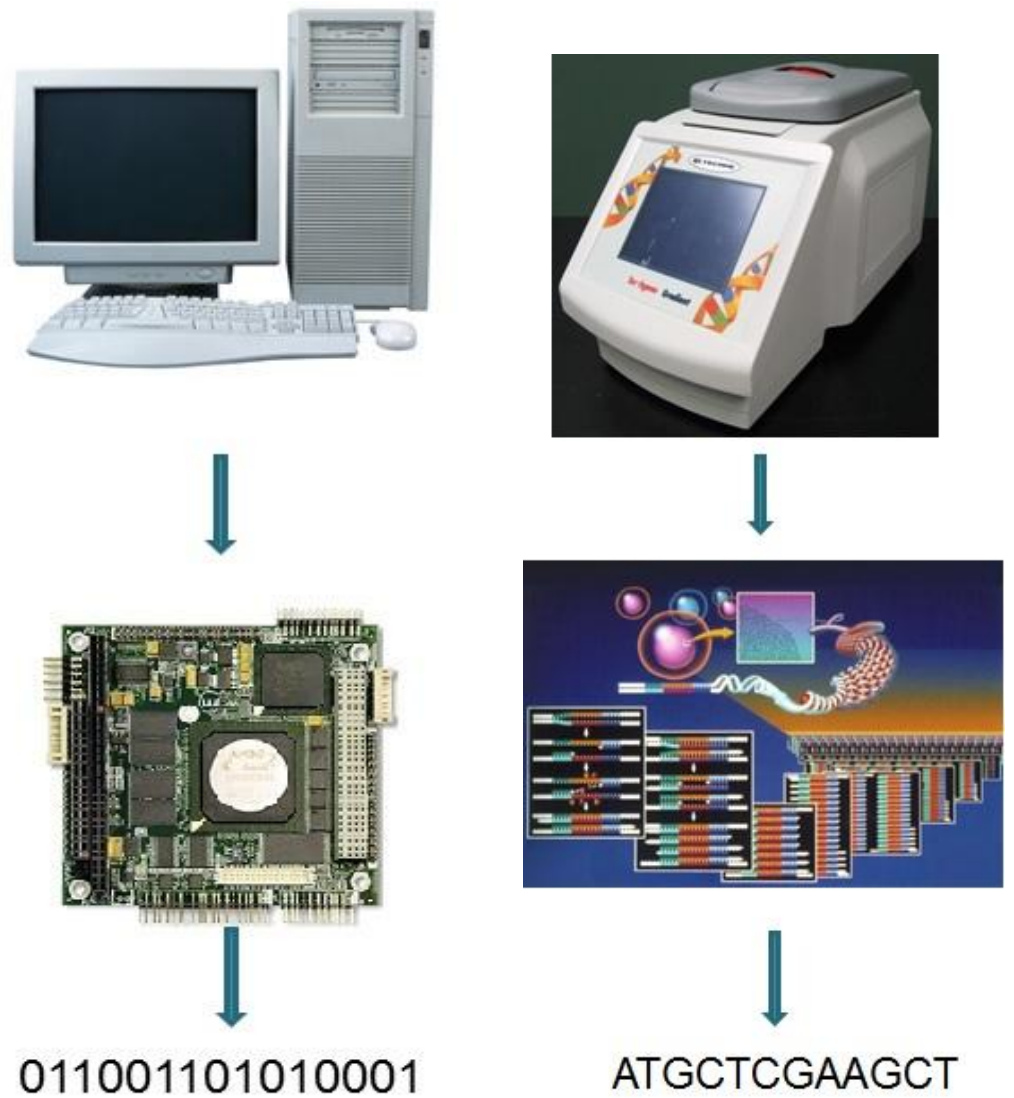

ATGCTCGAAGCT

Fig2. Comparing between the Silicon-based and DNA-based computer inputs

Using theDNA Computing, the more difficult problems will solved with higher accuracy and speed, comparing the current computers (table 1).

Table1. Comparison between the DNA-based and silicon-based computers

\begin{tabular}{|c|c|c|}
\hline مبتئى بر سيايكون & مبنّى بر DNA & معيار مقايسه \\
\hline سيليكون و مواد غير آلى ديگر & مواد بيولوزيك مانند اسيدهاى & اجز اى سازنده \\
\hline تزثيبى و موازى بصورت & بردازش موازى بصورث & طر ح بِردازشى \\
\hline $10^{12}$ & $10^{14}$ & حداكثر تعداد اعمال در ثانيه \\
\hline 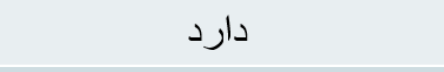 & 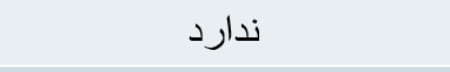 & مشكل اثر كوانتمى \\
\hline دارد & ن & اجزاى سمى \\
\hline 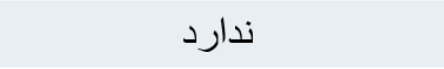 & 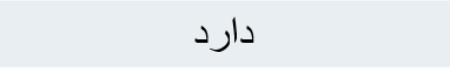 & بهينكى انرزى \\
\hline
\end{tabular}




\section{Literature Review about The Biology-based Computers}

- In 1994, Adelman proposed that DNA strings can used in Hamilton (TSP) problem solving. He did some attempts in finding the shortest path by the DNA strings

- In 1997, Quyang presented an empirical solution for classified problems based on biology and molecule.

- In 2000, Liu designed a model for DNA-based computers called Surface-base DNA computing. He could solve the Satisfiability problem by that model.

- In 2001, Wu analyzed the Surface-base DNA computing system and modified it.

- In 2001, Benenson designed a machine based on biology molecules, which was programmable and could process some commands automatically.

\section{Material and Methods}

In the following section, the Adelman model will explained. In addition, it should said that DNA strings made in Tarbiat-E- ModarresUnversity from Organic materials to implement the Adelman method and solve its flaws.

Adelman Suggested algorithm implementation in lab using the DNA, solving the TSP problem:

Hamilton Path: a path that crosses all vertices and passes each vertex once. This problem is a kind of NP-Complete problems. Importance of this problem is that if it solved by DNA strings, the DNA-Based computers can used for other problems too. Adelman algorithm performs as below:

$>$ For a graph with $\mathrm{n}$ vertices

1) Provide a random path set in graph

2) For each path in set:

$>$ Evaluate that path started at considered vertex and end at it. If it is not then eliminate the path.

$>$ Evaluate that path passes $n$ vertices correctly. If it is not then eliminate the path.

$>$ For each vertex, evaluate that path crosses it. If it is not then eliminate the path.

3) If set is not empty then there is one Hamilton path, otherwise there is no Hamilton path.

For example this algorithm used for a directed graph with four vertex and six edge. Study problem is the determination of a Hamilton path from Atlanta as the source vertex and Detroit as the destination.

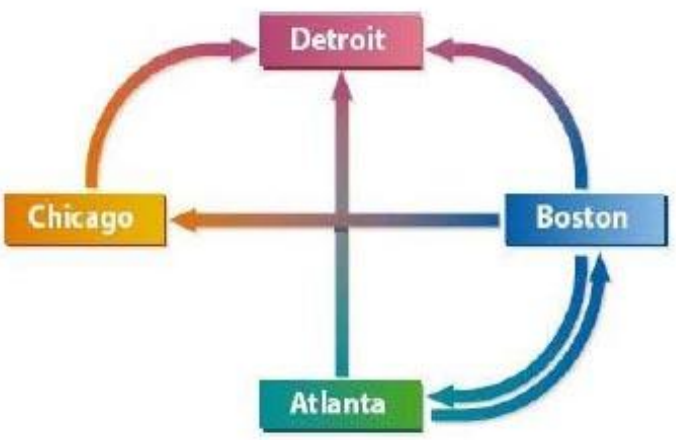

Fig3. Hamilton problem between the Atlanta and Detroit

The problem coded by the DNA strings and needed information remade by them (table 2).

- In a DNA graph, each vertex is a sequence of organic bases.

- Each edge is a sequence, consists of second half source vertex and first half destination vertex.

Table2. Each city DNA string and its complement string of each one

\begin{tabular}{lll}
\hline CIIY & DNANAME & COMPLEMENT \\
\hline ATLANTA & ACTTGCAG & TGAACGTC \\
\hline BOSTON & TCGGACTG & AGCCTGAC \\
\hline CHICAGO & GGCTATGT & CCGATACA \\
\hline DETROIT & CCGAGCAA & GGCTCGTT \\
\hline FLIGHT & DNAFLIGHTNUMBER \\
\hline ATLANTA - BOSTON & GCAGTCGG \\
\hline ATLANTA - DEIROIT & GCAGCCGA \\
\hline BOSTON- CHICAGO & ACTGGGCT \\
\hline BOSTON - DETROIT & ACTGCCGA \\
\hline BOSTON - ATLANTA & ACTGACTT \\
\hline CHICAGO-DETROIT & ATGTCCGA
\end{tabular}


How did DNA find the path in Adelman method?

- Adelman provided the vertices complement and edges as DNA string form.

- He put $10^{14}$ molecule from each different string in test tube.

- He obtained the answer by a fifteenth of teaspoon of solution and about one second while the answer obtaining was lasting about 54 second by the general methods.

In present section some definitions expressed about the parallel processing, that is one of the DNA-based computer benefits than Silicon-based computers.

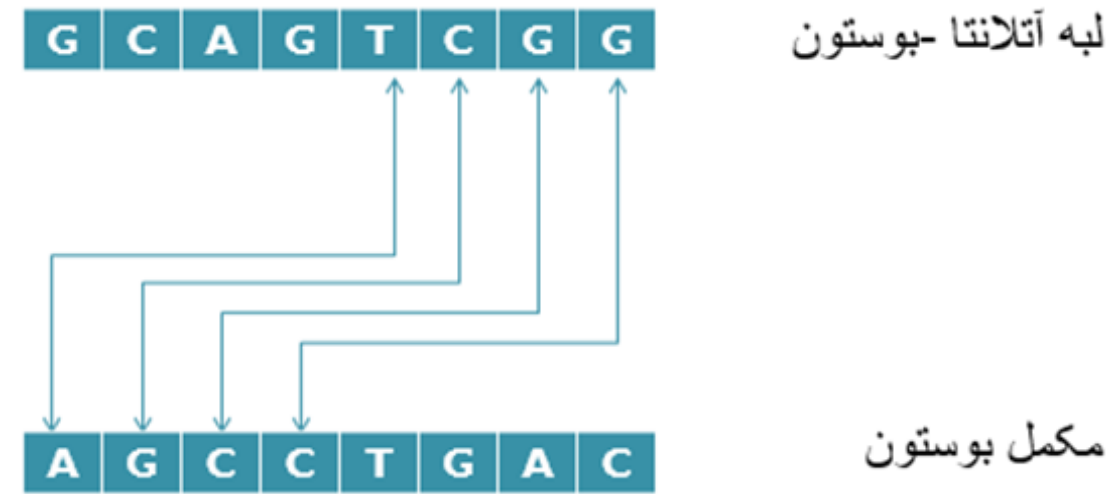

Fig4. Edge path from Atlanta to Boston and complement string of Boston

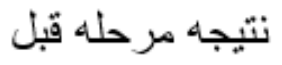

\begin{tabular}{l|l|l|l|l|l|l|l|}
$\mathbf{G}$ & $\mathbf{C}$ & $\mathbf{A}$ & $\mathbf{G}$ & $\mathbf{T}$ & $\mathbf{C}$ & $\mathbf{G}$ & $\mathbf{G}$ \\
\hline
\end{tabular}
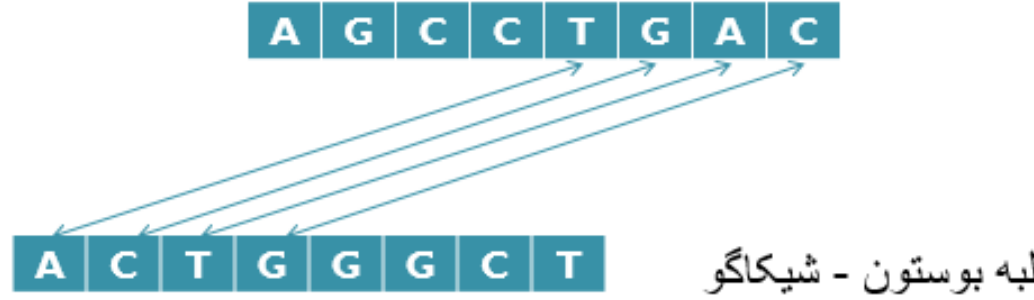

حاصل تلفيق

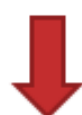

\begin{tabular}{l|l|l|l|l|l|l|l|}
$\mathbf{G}$ & $\mathbf{C}$ & $\mathbf{A}$ & $\mathbf{G}$ & $\mathbf{T}$ & $\mathbf{C}$ & $\mathbf{G}$ & $\mathbf{G}$ \\
\hline
\end{tabular}

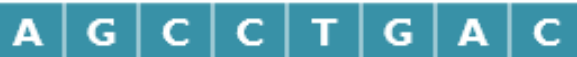

Fig5. Finding the next paths and vertices via each vertex complement.

Therefore and by a simultaneous transaction among the billions of molecules, the whole paths made. This biologic reaction shows a huge parallel process.For study problem the only answer is Atlanta-BostonChicago and Detroit; therefore a molecule with below sequence is the answer (figure 6).

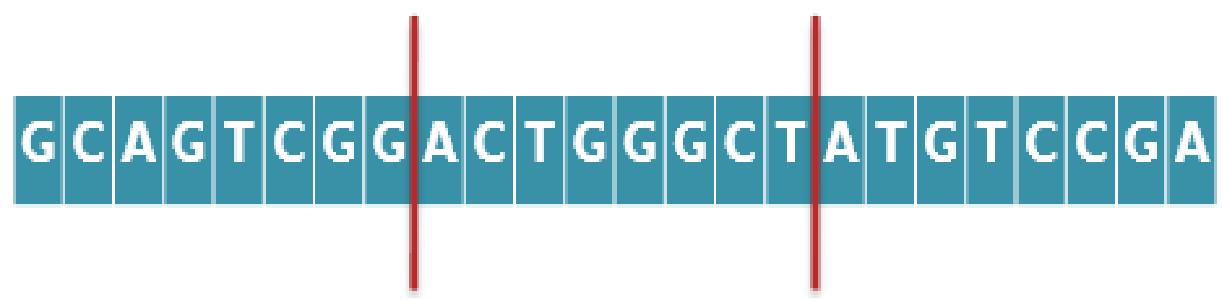

Fig6. Final string(Atlanta-Boston- Chicago and Detroit) 


\section{Adelman Method flaws:}

\section{Results}

Although Adelman was sure about the answer, however 100 Trillion other molecules were not the answer. Therefore, a way should found to eliminate the non-Hamilton paths. This flaw solved by the PCR technique (genetic and biologic profession). PCR is the abbreviation of Polymerase Chain Reaction. Totally, the PCR called to the increasing of DNA little amount methoduntil the consideration by the popular and simple laboratory methods.

Solving this problem, the below steps done in lab:

- In section 2 of step 2, it should evaluated that path passes the n vertex correctly.

- A path passed all vertices that has correct length (here the length is 24).

- Using the Electrophoresis gel, the paths with correct length selected.

As an example a non-Hamilton path, that should eliminated, presented for more explanation:

$>$ A non-Hamilton path is Atlanta-Boston-Atlanta-Detroit (figure 7) because:

- The source and destination are correct.

- The path length is correct.

- Nevertheless, it does not pass all vertices.

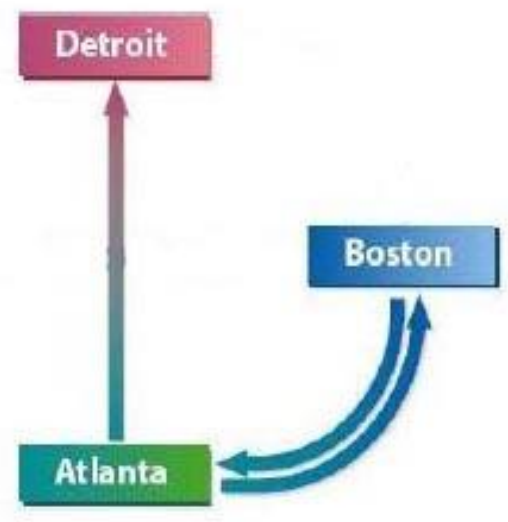

Fig7. Atlanta-Boston-Atlanta-Detroit Path

Separating the non-Hamilton paths from Hamilton ones, the following steps done:

- First vertex complement attached to the iron ball

- Ball located in solution.

- The strings contain that vertex stick to the ball.

- Solution remains will be discarded

- This step performed for all vertices

- The strings do not have one of the vertices will be discarded

- Complete the 2-3 step.

- If there were a string in solution, it is a Hamilton path (figure 8).

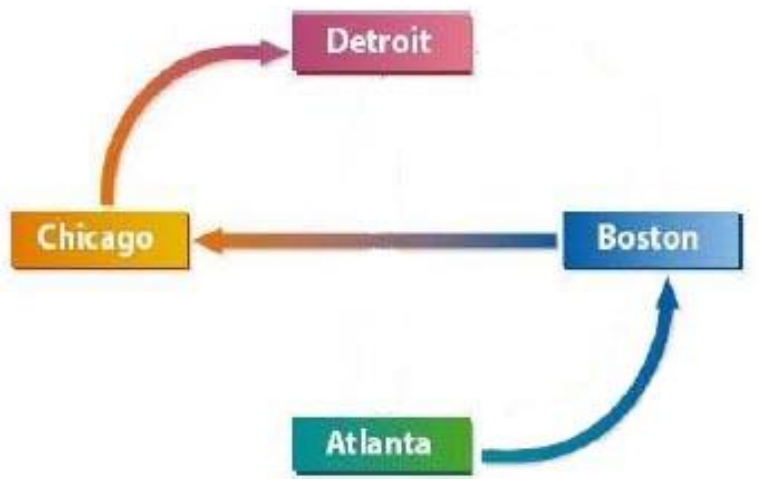

Fig8. The only Hamilton path of problem 
At the end of step 3 that is the end of algorithm, only one path will remain.

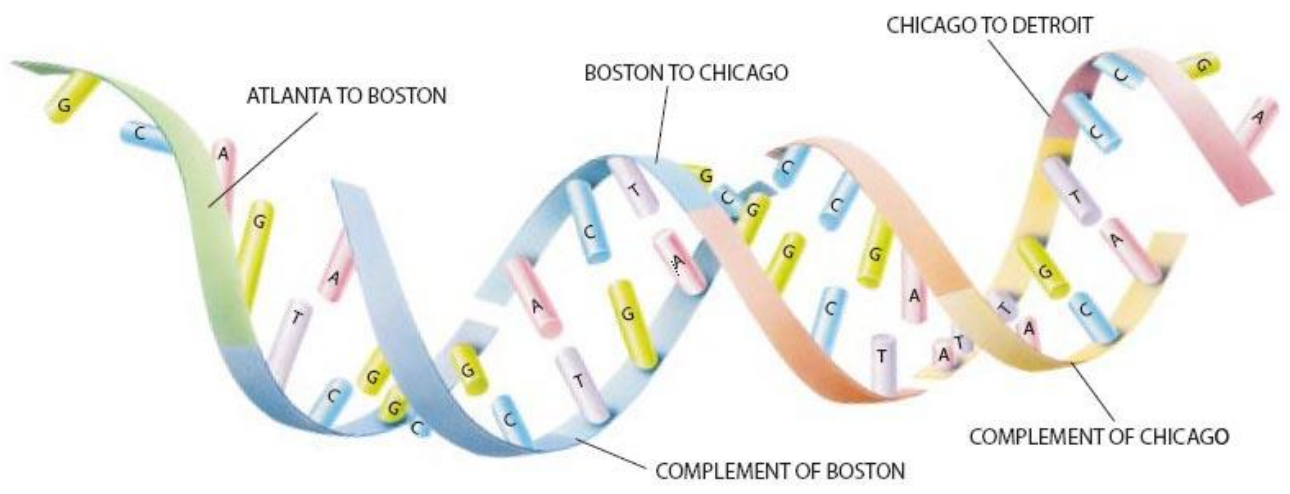

Fig9. Hamilton path from Atlanta to Detroit along with all vertices complement

At the end, three benefits of DNA-based computers than Silicon-based one are huge amount of savable information in each 1 gram DNA, ability of parallel processing and high energy efficiency.

- Capacity of information saving in one gram DNA (figure 10)

\section{1 gram}

4,000,000,000,000,000,000,000 bits

Fig10. Capacity of information saving in one gram DNA

- Parallel processing ability (figure 11 ), one $\mu$ moll of DNA: $10^{26}$ reactions.

\section{Joule}

\section{0,000,000,000,000,000,000 Operations}

- $\quad$ High efficiency of Energy

Fig11. Parallel processing ability

At the end it can be asked that what other works can done with DNAs?

\section{References}

[1] Adelman L. Molecular computation of solutions to combinational problems[J]. Science, 1994, 266: 1021-1024.

[2] Ouyang, Q. et al. DNA solution of the maximal clique problem. Science, 1997, 278:542.

[3] Liu, Q. et al. DNA computing on surfaces. Nature, 2000, 403: 175.

[4] Wu, H. An improved surface-based method for DNA computation. Biosystem, 2001, 59:1.

[5] Benenson, Y. et al. Programmable and autonomous computing machine made of biomolecules. Nature, 2001,414:430.

[6] https://en.wikipedia.org/wiki/Polymerase_chain_reaction 